\title{
Relationship Analysis between Runoff of Dadu River Basin and El Niño
}

\author{
Zujian Zou ${ }^{1, \mathrm{a}}$, Yubin $\mathrm{He}^{1}$ \\ ${ }^{1}$ Dadu River Hydropower Development Co., 610041 Chengdu, China
}

\begin{abstract}
The Dadu River Basin is located in the transitional zone between the Qinghai-Tibet Plateau and the Sichuan Basin. It is alternately affected by various weather systems such as the western Pacific subtropical high, the Qinghai-Tibet high (anti-cyclone), the southwest warm and humid air current, and the southeast monsoon. The western Pacific subtropical high is one of the main influencing factors of rainfall runoff in the basin. During the El Niño period, the western Pacific subtropical high moved eastward and the position was southward. The warm and humid airflow and the southeast monsoon northward changed, and the rainfall runoff in the Dadu River Basin changed.By analyzing the development of the El Niño phenomenon, Divide an El Niño process into different stages of occurrence, development, and end. Combining the characteristics of the Dadu River runoff in each stage, Studying the runoff situation of the Dadu River Basin under different strengths and weaknesses of the El Niño phenomenon. Using the correlation method to establish a model of the relationship between the abundance of the Dadu River Basin and the El Niño strength and weakness. Providing new ideas and new methods for the accurate prediction of the incoming water of the Dadu River under the abnormal climatic conditions of El Niño. It provides technical support for reservoir dispatching, flood control dispatching and economic dispatching of cascade hydropower stations, and provides experience for other river basins to cope with complex climate situations and improve water regime forecasting levels.
\end{abstract}

\section{Introduction}

El Niño is an important climate anomaly. Its name originated in Spanish and originally referred to the abnormal warming of cold currents on the west coast of South America around Christmas ${ }^{[1]}$. This phenomenon is the main cause of intense heavy rains on the northern coast of South America. In the 1970s, as climatologists continued to study the El Niño phenomenon deeoly, it was found that every time the El Niño phenomenon occurred, a series of significant changes will occur in the global climate 。 Therefore, the El Niño phenomenon has become a research hotspot in the climate and related fields, as well as an important basis for researching, exploring and predicting global climate change.

Related research shows that the El Niño phenomenon is one of the most important climate anomalies in the Pacific. The main mechanism is the increase of sea surface temperature in the eastern Pacific, which leads to a decrease in the temperature gradient in the eastern and western Pacific. The Walker circulation weakened, and more surface warm seawater remained in the eastern Pacific after the seawater flow slowed down. The relative temperature in the eastern Pacific continued to rise, allowing El Niño to maintain itself for a long time ${ }^{[2]}$. During the El Niño period, the East Asia region on the west coast of the Pacific Ocean experienced changes in weather systems such as monsoon and subtropical highs, and temperatures and rainfall were different from normal.
The Dadu River Basin, located on the eastern edge of the Qinghai-Tibet Plateau, was significantly affected, and the runoff was abnormally changed. further more, the climate situation and topography of the Dadu River Basin are the one of Most complicated in the world. The above factors lead to the Dadu River Basin Relevant climate and water forecasting are one of the major difficult areas in China and the world.

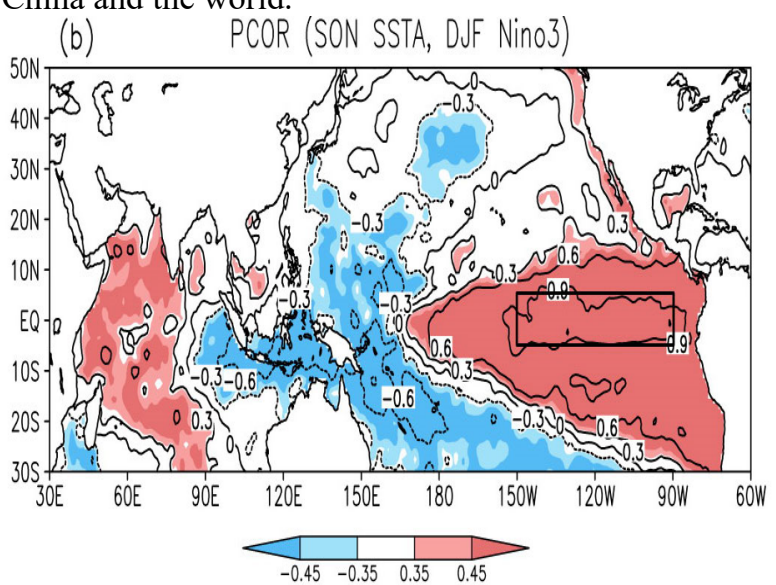

Fig.1. Schematic diagram of the SST anomalies during the El Niño period (this map is taken from the National Climate Center).

\section{Analysis of Climate \& Runoff in Dadu River Basin}

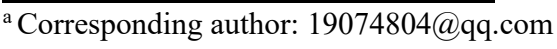




\subsection{Watershed climate characteristics}

The Dadu River Basin covers an area of $77,400 \mathrm{~km}^{2}$ and has a total length of $1,062 \mathrm{~km}$. The entire basin has a north-south crank-funnel type with a north-south span of five latitudes $\left(\mathrm{N} 33^{\circ} 30^{\prime}-\mathrm{N} 29^{\circ} 40^{\prime}\right)$ and east-west spans of four longitudes $\left(\mathrm{E} 100^{\circ} 20-\mathrm{E} 103^{\circ} 40^{\prime}\right)$. The Dadu River Basin is located in the transition zone between the Qinghai-Tibet Plateau and the Sichuan Basin. The main topography includes plateaus, alpine meadows, alpine valleys and hilly gentle slopes. The terrain is particularly complex and the climate within Dadu River basin varies widely.

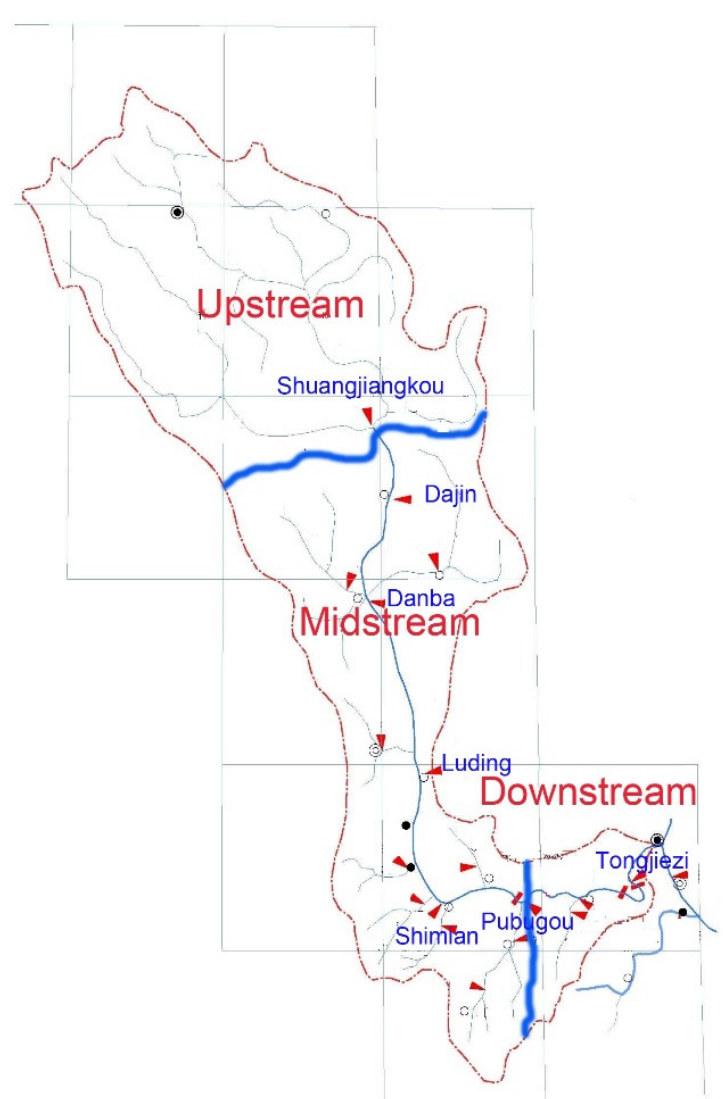

Fig.2. Dadu River Basin.

\subsection{Analysis of the Mechanism of the Influence of EI Niño in the Dadu River Basin}

The Dadu River Basin is affected by the alternating effects of the western Pacific subtropical high, the Qinghai-Tibet Plateau high-pressure (anti-cyclonic), the southwest warm and humid air current, and the southeast monsoon. The western Pacific subtropical high is one of the main influencing factors of rainfall runoff in the Dadu River Basin ${ }^{[3]}$. In the summer, the warm and humid air currents of the Indian Ocean from the Indian Ocean and the Bay of Bengal and the monsoon from the South China Sea pass through the Dadu River Basin from south to north, and rise and cool after encountering the mountain plateau, forming rainfall runoff.

During the El Niño period, the western Pacific subtropical high moved eastward and the position was southward. The warm and humid airflow and the southeast monsoon northward path were Different from normal year.This change causes rainfall runoff in the Dadu River Basin changed, which was the main mechanism of El Niño's influence on the Dadu River runoff $^{[4]}$.

\subsection{Runoff data analysis and research section selection}

As early as 1937, the Tongjiezi Hydrological Station was established to carry out hydrological testing. 1950s, the basic hydrological stations such as Danba and Luding were successively established by the hydrological department to form the Dadu River mainstream hydrological monitor network.

Table 1. Statistical data of runoff data of main controlled hydrological stations in the main stream of Dadu River.

\begin{tabular}{|c|c|c|c|c|c|c|}
\hline Site & Dajin & Danba & Luding & Shimian & Pubugou & Tongjiezi \\
\hline Data & $1959 \sim$ & $1959 \sim$ & $1959 \sim$ & $1954 \sim$ & $1937 \sim$ & $1937 \sim$ \\
period & 2016 & 2016 & 2016 & 2016 & 2016 & 2016 \\
\hline Years & 58 & 58 & 58 & 63 & 80 & 80 \\
\hline
\end{tabular}

The El Niño cycle is about 2 to 7 years, and hydrometeorology cycle is more than 10 years. To eliminate local specificity and ensure the universal applicability of research results, the data series is generally required to reach more than 30 years. It can be seen from the table that the six-station data series are all over 50 years old and can be used for regular analysis. The data of the two stations of Waterfall Ditch and Tongjiezi reached 80 years, which is better than the other four stations. Further considering the location and control area of each station, Daiking, Danba, and Luding are located in the upper reaches of Dadu River Basin, and the control area is small, which is not representative of the full-basin runoff. The Tongjiezi runoff is obviously affected by the upstream Pubugou-reservoir, and the runoff data cannot be directly used. After considering the relevant factors, the analysis of the El Niño-Runoff Coupling Relationship is carried out by selecting the section of the waterfall ditch.

\section{Runoff-El Niño Coupling Analysis in the Dadu River Basin}

\subsection{Analysis of the Relationship between Runoff and EI Niño}

According to statistics, since the first record in the 1950s, there have been 19 more typical El Niño events. Among them, the three El Niño strengths were the highest in 1982-1983, 1997-1998, and 2014-2016, reaching a superstrong level. From 1957 to 1958 and 1972 to 1973 , the intensity of the 8 times reached a medium strong level, and the intensity of other events was weak.

Among them, the development process of the strong El Niño phenomenon from 1997 to 1998 is the most typical. Beginning in February 1997, the SST in the Middle East and Pacific Ocean continued to rise abnormally, and the local area increased by 3 degrees Celsius. The initial disturbance caused the positive 
feedback loop to superimpose and the El Niño phenomenon appeared. By December 1997, the temperature increase in local parts of the eastern Pacific reached 5 degrees Celsius, and the Niño34 in the Middle East and the Pacific reached 2.8 or more, making it the strongest El Niño phenomenon in the twentieth century.

Table 2. Statistical Table of Major El Niño Phenomena since the $1950 \mathrm{~s}$.

\begin{tabular}{|c|c|c|c|}
\hline $\begin{array}{c}\text { Serial } \\
\text { number }\end{array}$ & Start and end date & Intensity & $\begin{array}{c}\text { Duration(M } \\
\text { onths) }\end{array}$ \\
\hline 1 & Aug.1951 Jan. 1952 & weak & 6 \\
\hline 2 & Apr.1957 Jul.1958 & moderate & 16 \\
\hline 3 & Jul.1963 Jan. 1964 & weak & 7 \\
\hline 4 & May 1965 May 1966 & moderate & 14 \\
\hline 5 & Oct.1968 Feb.1970 & weak & 17 \\
\hline 6 & May 1972 Mar.1973 & strong & 11 \\
\hline 7 & Sept.1976 Feb.1977 & weak & 6 \\
\hline 8 & Sept.1977 Feb.1978 & weak & 6 \\
\hline 9 & Sept.1979 Jan. 1980 & weak & 5 \\
\hline 10 & Apr.1982 Jun.1983 & Super- strong & 15 \\
\hline 11 & Aug.1986 Feb. 1988 & moderate & 19 \\
\hline 12 & May 1991 Jun. 1992 & moderate & 14 \\
\hline 13 & Sept.1994 Mar.1995 & moderate & 7 \\
\hline 14 & Apr.1997 Apr.1998 & Super- strong & 13 \\
\hline 15 & May $2002 \sim$ Mar.2003 & moderate & 11 \\
\hline 16 & Jul.2004 Jan.2005 & weak & 7 \\
\hline 17 & Aug.2006 Jan.2007 & weak & 6 \\
\hline 18 & Jun.2009 Apr.2010 & moderate & 11 \\
\hline 19 & Oct.2014 May 2016 & Super-strong & 19 \\
\hline
\end{tabular}

According to the runoff characteristics of different periods of the Dadu River Basin during the year, one year is divided into dry season before flood season(pre-flood season,Jan.-May), flood season (Jun.-Sept.), and dry season after flood season (post-flood season,Oct.-Dec.). According to Table 2, we find the following facts:

a. Low-intensity El Niño phenomenon generally begins in the middle and late stages of the year, and ends in pre-flood season of second year.

b. Moderate and above-intensity El Niño events last longer and generally occur in pre-flood season, lasting for more than 10 months, ending in second year(flood season or post-flood season).

For example, Fig. 3. shows the 1997-98 super El Niño process.

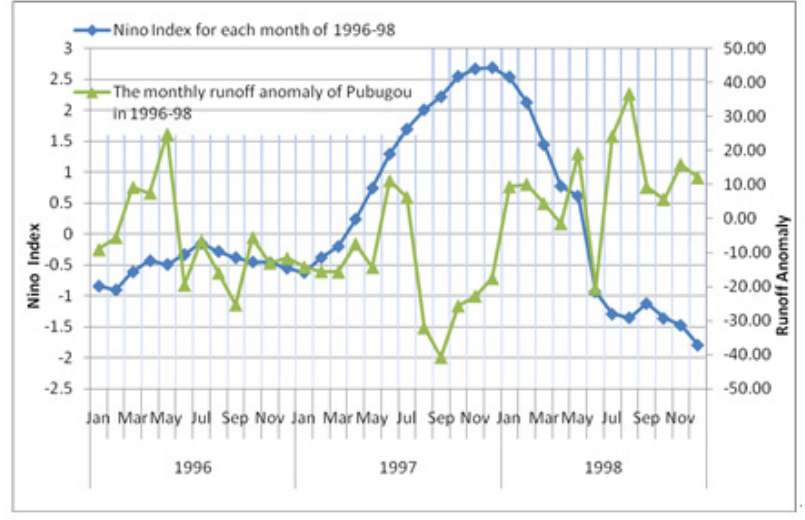

Fig.3. Process chart of the Nino index during the Super-strong El Niño in 1997 -98.

Combining hydrological phenomena with the characteristics of flood season and dry season as a cycle, from the perspective of meteorological and hydrological coupling, the entire impact cycle of El Niño is divided into three stages, so as to correspond to the reservoir scheduling period.

Table 3. El Niño Impact Period Allocation Table Based on Meteorological-Water Condition Coupling.

\begin{tabular}{|c|c|}
\hline Stage(T) & preiod \\
\hline 1 & Month of occurrence - Oct. \\
\hline 2 & Oct.- May of the following year \\
\hline 3 & May of the following year-Nov. \\
\hline
\end{tabular}

According to the different impact cycle, the statistics of the inflow of the Pubugou Reservoir were counted and expressed as anomalies (\%) (Table 4). It is found that the El Niño phenomenon with different intensities has an impact on the incoming water in the Dadu River Basin, and the negative impact is the main feature. Among them, strong and super-strong El Niño phenomenon has the most significant negative impact on the incoming water in the Dadu River Basin. The impact on the runoff in the $\mathrm{T}=1$, 2 , and 3 stages is $-11.95 \%,-6.78 \%$, and $-5.57 \%$, respectively.

Table 4. El Niño impact Pubugou flow anomaly statistics.

\begin{tabular}{|c|c|c|c|}
\hline Stage & $\begin{array}{c}\text { Runoff } \\
\text { anomalies } \\
(\mathbf{T}=\mathbf{1})\end{array}$ & $\begin{array}{c}\text { Runoff } \\
\text { anomaly } \\
\mathbf{( T = 2 )}\end{array}$ & $\begin{array}{c}\text { Runoff } \\
\text { anomalies } \\
\mathbf{( T = 3 )}\end{array}$ \\
\hline $\begin{array}{c}\text { Weak } \\
(8 \text { times })\end{array}$ & $-7.33 \%$ & $-3.10 \%$ & $-2.78 \%$ \\
\hline $\begin{array}{c}\text { Moderate } \\
(7 \text { times })\end{array}$ & $-6.43 \%$ & $-5.72 \%$ & $1.15 \%$ \\
\hline $\begin{array}{c}\text { Strong, Super- } \\
\text { strong } \\
(4 \text { times })\end{array}$ & $-11.95 \%$ & $-6.78 \%$ & $-5.57 \%$ \\
\hline $\begin{array}{c}\text { Moderate and } \\
\text { above- } \\
\text { intensity } \\
(11 \text { times })\end{array}$ & $-8.44 \%$ & $-6.11 \%$ & $-1.29 \%$ \\
\hline
\end{tabular}


3.2 Construction of the generalized model of runoff and the EI Niño coupling in the Dadu River Basin
According to Table 4, the Dadu River has a relationship between runoff and the El Niño, and $\mathrm{S}$ is used to indicate the strength of the El Niño phenomenon. $S=1,2$, and 3 represent weak, medium, strong and above. F represents abundance of runoff of Dadu River Basin, as defined in Table 5 below.

Table 5. Pubugou flow abundance definition table.

\begin{tabular}{|c|c|c|c|c|c|c|}
\hline Anomaly & $\mathbf{- 1 5 \%} \sim \mathbf{- 1 0 \%}$ & $\mathbf{- 1 0 \%} \sim \mathbf{- 5 \%}$ & $\mathbf{- 5 \%} \sim \mathbf{0 \%}$ & $\mathbf{0 \%} \sim \mathbf{5 \%}$ & $\mathbf{5 \%} \sim \mathbf{1 0} \%$ & $\begin{array}{c}\mathbf{1 0} \% \sim \\
\mathbf{1 5 \%}\end{array}$ \\
\hline abundance (F value) & -3 & -2 & -1 & 1 & 2 & 3 \\
\hline
\end{tabular}

Then, Table 4 is converted into a relational matrix (Table 6).

Table 6. F-S-T relationship table.

\begin{tabular}{|c|c|c|c|}
\hline $\mathbf{S}$ & $\mathbf{T}=\mathbf{1}$ & $\mathbf{T}=\mathbf{2}$ & $\mathbf{T}=\mathbf{3}$ \\
\hline $\mathbf{S}=\mathbf{1}$ & $\mathrm{F}=-2$ & $\mathrm{~F}=-1$ & $\mathrm{~F}=-1$ \\
\hline $\mathbf{S}=\mathbf{3}$ & $\mathrm{F}=-2$ & $\mathrm{~F}=-2$ & $\mathrm{~F}=1$ \\
\hline
\end{tabular}

Constructing a generalized model between the runoff and the strength of El Niño, the development stage:

$$
F=f(S, T)
$$

Through regression analysis, the correlation coefficient between $\mathrm{F}$ and $\mathrm{S}$ and $\mathrm{T}$ is 0.74 , which has a high positive correlation. It shows that runoff of Dadu River Basin is significantly affected by the El Niño phenomenon, and the impact is relatively stable.

\subsection{Exploring the quantitative model of runoff and the El Niño coupling in the Dadu River Basin}

The generalized model can be used to answer the situation and extent of runoff of the Dadu River in different intensity levels and different impact periods of El Niño. In the actual scheduling process, it is often necessary to further predict the specific magnitude of runoff. Therefore, constructing a quantitative model that can output specific runoff anomalies has practical and practical significance. El Niño's main characteristic parameters include peak intensity (usually reflected by the Niño34 index), peak occurrence time, duration, etc., which can be obtained from the meteorological department (predicted or actual).

By definition, the Niño34 index is the Sea temperature anomaly of the intersection of the Niño3 and Niño4 in the Pacific Ocean, which directly reflects the physical origin and intensity of El Niño, so it is selected as the modeling input variable. The Niño34 index released by the National Climate Center is shown in Table 7.

Table 7. The main El Niño phenomenon Niño34 index table since the $1980 \mathrm{~s}$

\begin{tabular}{|c|c|c|c|}
\hline $\begin{array}{c}\text { Serial } \\
\text { number }\end{array}$ & Start and end date & Intensity & $\begin{array}{c}\text { Niño34 } \\
\text { index }\end{array}$ \\
\hline 1 & Apr.1982 Jun.1983 & $\begin{array}{c}\text { Super- } \\
\text { strong }\end{array}$ & 2.78 \\
\hline
\end{tabular}

\begin{tabular}{|c|l|c|c|}
\hline 2 & Aug.1986 Feb.1988 & moderate & 1.74 \\
\hline 3 & May 1991 Jun.1992 & moderate & 1.83 \\
\hline 4 & Sept.1994 Mar.1995 & moderate & 1.3 \\
\hline $\mathbf{5}$ & Apr.1997 Apr.1998 & $\begin{array}{c}\text { Super- } \\
\text { strong }\end{array}$ & $\mathbf{2 . 6 6}$ \\
\hline 6 & May 2002 $\sim$ Mar.2003 & moderate & 1.62 \\
\hline 7 & Jul.2004 Jan.2005 & weak & 0.75 \\
\hline 8 & Aug.2006 Jan.2007 & weak & 1.08 \\
\hline 9 & Jun.2009 Apr.2010 & moderate & 1.72 \\
\hline $\mathbf{1 0}$ & Oct.2014 May 2016 & $\begin{array}{c}\text { Super- } \\
\text { strong }\end{array}$ & $\mathbf{2 . 8 1}$ \\
\hline
\end{tabular}

The eigenvalues of El Niño phenomenon from 1 to 10 are selected as the model source data, and the correlation is obtained by the curve fitting rate to obtain the coupled quantitative model $\mathrm{F}(\mathrm{N})$.

$$
F(N)=\left\{\begin{array}{l}
7.449 \ln N-16.64,(T=1) \\
2.188 \ln N-9.544,(T=2) \\
1.406 \ln N-0.172,(T=3)
\end{array}\right.
$$

$\mathrm{N}$ : Niño34 index (peak intensity).

\subsection{Quantitative model graphics check.}

The relevant data points are plotted on the scatter plot (Fig.4.) for graphical verification. The related graph shows that the model can reflect the relationship between the Niño34 index and runoff anomaly.

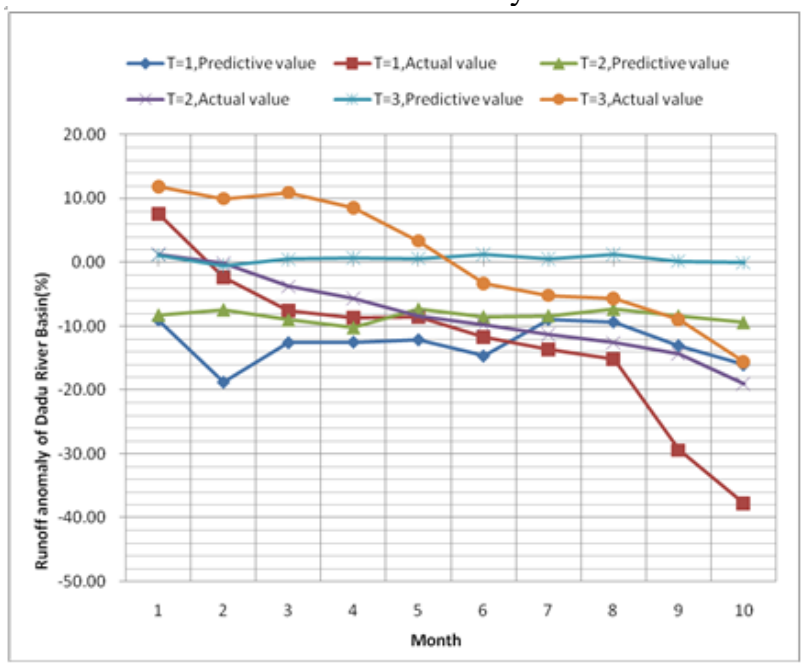

Fig.4. Process chart of the Nino index during the Super-strong El Niño in 1997 -98. 


\subsection{Quantitative model numerical verification.}

The quantitative model $\mathrm{F}(\mathrm{N})$ is numerically verified as shown in Table 8.

According to the verification results, when $\mathrm{T}=1$ (that is, the El Niño development year,flood season), the model has a prediction rate of $90 \%$, except for 1982-83, 2002-03, 2004-05, 2006-07, and the others absolute value of runoff anomaly deviation is within $10 \%$. When $\mathrm{T}=2$ (that is, the El Niño development year,post-dry season), the model has a $90 \%$ coincidence rate, and the absolute value of all El Niño phenomenon is within $10 \%$. When $\mathrm{T}=3$ (that is, El Niño ends the annual flood season), the model has a 50\% coincidence rate.

Table 8. Quantitative model numerical verification table $(\mathrm{T}=1,2,3)$.

\begin{tabular}{|c|c|c|c|c|c|c|c|c|c|c|c|}
\hline \multirow{2}{*}{$\begin{array}{c}\text { Serial } \\
\text { number }\end{array}$} & \multirow{2}{*}{$\begin{array}{l}\text { Start and end } \\
\text { date }\end{array}$} & \multirow{2}{*}{$\mathrm{N}$} & \multicolumn{3}{|c|}{$\mathbf{F}(\mathbf{T}=\mathbf{1})$} & \multicolumn{3}{|c|}{$F(T=2)$} & \multicolumn{3}{|c|}{$F(T=3)$} \\
\hline & & & Actual & Predictive & $\begin{array}{c}\text { Match } \\
\text { (Yes/No) }\end{array}$ & Actual & Predictive & $\begin{array}{c}\text { Match } \\
\text { (Yes/No) }\end{array}$ & Actual & Predictive & $\begin{array}{c}\text { Match } \\
\text { (Yes/No) }\end{array}$ \\
\hline 1 & $\begin{array}{l}\text { Apr.1982 } \\
\text { Jun.1983 }\end{array}$ & 2.78 & 7.58 & -9.02 & Yes & -8.36 & -7.31 & Yes & -3.32 & 1.27 & No \\
\hline 2 & $\begin{array}{l}\text { Aug.1986 } \\
\text { Feb.1988 }\end{array}$ & 1.74 & -8.67 & -12.51 & Yes & -11.36 & -8.33 & Yes & 3.32 & 0.61 & Yes \\
\hline 3 & $\begin{array}{l}\text { May 1991 } \\
\text { Jun.1992 }\end{array}$ & 1.83 & -8.53 & -12.14 & Yes & 1.26 & -8.22 & No & 8.53 & 0.68 & Yes \\
\hline 5 & $\begin{array}{l}\text { Apr.1997 } \\
\text { Apr.1998 }\end{array}$ & 2.66 & -15.17 & -9.35 & Yes & -0.16 & -7.40 & Yes & 11.85 & 1.20 & Yes \\
\hline 6 & $\begin{array}{l}\text { May 2002 } \\
\text { Mar.2003 }\end{array}$ & 1.62 & -29.38 & -13.05 & Yes & -9.78 & -8.49 & Yes & 10.90 & 0.51 & Yes \\
\hline 7 & $\begin{array}{l}\text { Jul.2004 } \\
\text { Jan.2005 }\end{array}$ & 0.75 & -2.37 & -18.78 & Yes & -5.68 & -10.17 & Yes & 9.95 & -0.58 & No \\
\hline 8 & $\begin{array}{l}\text { Aug.2006 } \\
\text { Jan.2007 }\end{array}$ & 1.08 & -37.76 & -16.07 & Yes & -19.09 & -9.38 & Yes & -15.64 & -0.06 & Yes \\
\hline 9 & $\begin{array}{l}\text { Jun.2009 } \\
\text { Apr.2010 }\end{array}$ & 1.72 & -7.58 & -12.60 & Yes & -14.35 & -8.36 & Yes & -5.21 & 0.59 & No \\
\hline 10 & $\begin{array}{l}\text { Oct.2014 } \\
\text { May } 2016\end{array}$ & 2.81 & -13.66 & -8.94 & Yes & -12.62 & -7.28 & Yes & -5.69 & 1.28 & No \\
\hline
\end{tabular}

Quantitative model graph verification and numerical verification results show that in the El Niño year, the important eigenvalue Niño34 index has a significant correlation with the abundance of the Dadu River Basin. In the development of El Niño, the forecasting accuracy rate of the model is $90 \%$. The numerical prediction results are highly consistent and can be used for dispatching when forecasting runoff is in the normal to dry range. When runoff is especially dry, the numerical prediction shows a large deviation. In the end of the El Niño period, the correlation between the Niño34 index and the Dadu River Basin was weakened, and the prediction accuracy of the model was $50 \%$. The predicted values fluctuate randomly around the mean value of the runoff., and the reference was correspondingly weakened.

\section{Conclusion}

As the first phase of hydropower station dispatching, runoff forecasting plays an important role in the power production of hydropower stations. However, there are many factors affecting runoff and uncertainties. It is difficult to accurately quantify long-term forecasting, which has become an obstruct to improve economic dispatching and enhance flood control in river basins. In recent years, the frequent occurrence of global climate anomalies.the El Niño phenomenon has become an important factor affecting runoff of the basin. Through the long-term data correlation analysis, the runoff-El Niño coupling generalization model of Dadu River Basin is proposed, and the quantitative model is further constructed to provide reference for the formulation and scheduling decision of the basin scheduling scheme. The proposed data analysis and model construction method can be further promoted and applied to other river basins or industries.

\section{References}

1. Francis H. S. Chiew \& Thomas A. Mcmahon, Global ENSO-streamflow Teleconnection,Streamflow forecasting and Interannual Variability[J]. Hydrological Sciences Journal,2002,(3):505-522.

2. Mo Ruping,Zhang Yan,On The Mechanism Of Teleconnections Between El Niño And East Asian Atmospheric Circulation[J].Acta Meteorologica Sinica, 1988,(2):288-299.

3. Scott A. Stephens, D.L. Ramsay, Extreme cyclone wave climate in the Southwest Pacific Ocean: Influence of the El Niño Southern Oscillation and 
projected climate change. Global and Planetary Change,2014,(123):13-26.

4. Liu Yanxiang,Ji Guoliang, The Reflection of El Niño and Southwest-monsoon in the Radiation Budget of Earth-Atmosphere System over Qinghai-Xizang

Plateau. Formation and Evolution, Environmental Changes and Sustainable Development on the Tibetan Plateau,Xining China,1998. 